\title{
Preference and Experience of Colonic Examination for Participants Presenting to Hospitals with a Positive Fecal Immunochemical Test Result
}

This article was published in the following Dove Press journal: Patient Preference and Adherence

\author{
Takashi Kato' \\ Koichi Nagata ${ }^{2,3}$ \\ Junta Yamamichi ${ }^{4}$ \\ Soichi Tanaka ${ }^{5}$ \\ Tetsuro Honda ${ }^{6}$ \\ Norihito Shimizu ${ }^{7}$ \\ Kenichi Utano ${ }^{8}$ \\ Michiaki Hirayama 9 \\ Hiroshi Matsumoto ${ }^{10}$ \\ Shoichi Horita' \\ 'Department of Internal Medicine, \\ Hokkaido Gastroenterological Hospital, \\ Sapporo, Japan; ${ }^{2}$ Department of \\ Gastroenterology, Fukushima Medical \\ University School of Medicine, Fukushima, \\ Japan; ${ }^{3}$ Cancer Screening Center, National \\ Cancer Center Hospital, Tokyo, Japan; \\ ${ }^{4}$ Division of Hematology, Respiratory \\ Medicine and Oncology, Department of \\ Internal Medicine, Faculty of Medicine, Saga \\ University, Saga, Japan; ${ }^{5}$ Department of \\ Coloproctology, Matsuaikai Matsuda \\ Hospital, Hamamatsu, Japan; ${ }^{6}$ Department \\ of Gastroenterology, Nagasaki Harbor \\ Medical Center, Nagasaki, Japan; \\ ${ }^{7}$ Department of Radiology, Medical \\ Corporation Matsuoka Clinic, Nara, Japan; \\ ${ }^{8}$ Department of Coloproctology, Aizu \\ Medical Center, Fukushima Medical \\ University, Aizuwakamatsu, Fukushima, \\ Japan; ' Department of Gastroenterology, \\ Tonan Hospital, Sapporo, Japan; \\ ${ }^{10}$ Department of Gastroenterology, \\ Kawasaki Medical University School of \\ Medicine, Kurashiki, Japan
}

Correspondence: Takashi Kato Department of Internal Medicine, Hokkaido Gastroenterological Hospital, Sapporo, Hokkaido 065-004I, Japan

Tel +8 I I I-784- I8I I

Fax +8I II-784-1838

Email tkskato45@gmail.com
Purpose: Patients who test positive on the fecal immunochemical test (FIT) for colorectal cancer (CRC) are referred for colonoscopy for further diagnostic evaluation. Colonoscopy is not a perfect method and may be a challenge for some FIT-positive patients. Computed tomographic colonography (CTC) is an alternative method that is less invasive and allows examination of the whole colon. The study objective was to evaluate the preference of FITpositive patients for either colonoscopy or CTC for CRC examination.

Patients and Methods: Individuals older than 40 years with a positive FIT test at eight Japanese hospitals between December 2012 and July 2015 were invited to participate. Participants were given detailed information regarding colonoscopy and CTC before deciding on either examination. They completed questionnaires before the procedure regarding their preference and after the procedure regarding their experience.

Results: The pre- and post-questionnaires of 846 and 834 participants, respectively, were analyzed. Participants preferred colonoscopy over CTC (colonoscopy, 72\%; CTC, 28\%). The possibility of obtaining biopsy samples and removing colorectal polyps during the procedure was the main reason for colonoscopy selection. Patients selected CTC to reduce discomfort but reported that CTC bowel preparation was more burdensome than colonoscopy bowel preparation. The overall experience of the examination did not differ between the groups.

Conclusion: Colonoscopy is the standard examination for FIT-positive patients. However, when given a choice, almost one-third of participants chose CTC because they thought it would be a more "comfortable" examination. Clinicians should therefore be aware of patients' potential preference for noninvasive colorectal examinations.

Keywords: computed tomographic colonography, colonoscopy, patient preference, fecal immunochemical test

\section{Introduction}

Globally, colorectal cancer (CRC) ranks third in incidence and second in mortality among cancers, with an estimated 1.8 million cases and approximately 881,000 deaths occurring in 2018. ${ }^{1}$ Screening methods for CRC have been developed to decrease incidence rates and overall mortality rates. Population-based screening programs for CRC, such as the guaiac fecal occult blood test (gFOBT) or fecal immunochemical test (FIT), have since been implemented in many parts of the world, and colonoscopy is widely recommended for diagnostic evaluation in those with a positive FIT result. ${ }^{2,3}$ In about $5.6 \%$ of gFOBT-positive individuals, CRC is subsequently detected by colonoscopy, whereas adenomatous polyps are detected in $25.6 \%$ of this patient population. ${ }^{4}$ 
However, colonoscopy is not a perfect diagnostic method and may be a challenge for some FIT-positive patients. For example, a colonoscopy may be contraindicated or refused by some patients, ${ }^{5}$ and results may be incomplete because colonoscopic procedures may not achieve the target $90 \%$ cecal intubation rate, and even if they do, $10 \%$ of patients will still not undergo an examination of the entire colon. ${ }^{6}$ Colonoscopy can also result in complications, such as rectal bleeding or perforation of the colon. ${ }^{6}$ Additionally, in many countries, colonoscopic resources are inadequate for diagnostic workup of patients with a positive FIT result. ${ }^{3,7}$

Computed tomographic colonography (CTC) is safe, well-tolerated, and accurate for evaluation of cancer and advanced adenoma. ${ }^{8,9}$ In the United States, for patients at average or moderate risk for colorectal cancer, CTC is usually appropriate for colorectal cancer detection following a FIT-positive result. ${ }^{10}$ However, in Japan and Europe, CTC is currently not recommended as a triage examination prior to colonoscopy in patients with a FIT-positive result. ${ }^{11,12}$ CTC is only performed as an alternative examination for those patients who cannot undergo colonoscopy or for those in which the colonoscopy procedure did not result in examination of the entire colon. ${ }^{11,12}$

Several studies have reported on patient preference between colonoscopy and CTC by conducting questionnaires after the examinations. Many of these studies revealed CTC to be chosen by patients as the preferred method for potential future examination. ${ }^{9,13,14}$ However, these results do not reflect patients' pre-examination preferences because they were mainly based on the experience of the procedures obtained post-examination. To determine whether CTC is an acceptable test for FIT-positive patients, it is necessary to investigate why the patient being tested chose CTC instead of colonoscopy.

The purpose of this study was to evaluate the preference for either colonoscopy or CTC as the first examination for CRC in patients with FIT-positive results who do not have a contraindication and who have not previously refused either of these two types of diagnostic exams. In addition, we evaluated the patients' experience of the examination after it was performed.

\section{Methods}

\section{Participants}

A total of eight hospitals in Japan participated in this survey-based study, and institutional review board approval for the study was obtained from the ethical committees of Hokkaido Gastroenterology Hospital and all participating institutes. This study was registered with the UMIN Clinical Trials Registry (UMIN000009456; www.umin.ac.jp/ctr/index.htm; registered on 2012/12/04). Between December 2012 and July 2015, all individuals older than 40 years with a positive FIT result were invited to participate, and all voluntarily visited the participating sites for colorectal examination. The trial was performed in accordance with the Declaration of Helsinki. Participants were excluded if they presented any of the following conditions: serious medical conditions associated with an increased risk of complications from bowel preparation and colonoscopy or CTC; history of inflammatory bowel disease, Lynch syndrome, familial polyposis, or colorectal surgery; pregnancy; or severe psychiatric symptoms that would affect their ability to understand and complete a questionnaire. Participants were registered after providing written informed consent for prospective enrollment in the study.

Participants were given detailed information about colonoscopy and CTC in the form of a written document (Table S1 in Supplementary Material) that described all essential clinical information in plain language, including information on bowel preparation; sensitivity, acceptability, and length of procedure; sedation; cost of the examination; and information about the advantages and disadvantages of both examinations. In addition, all information was arranged side by side in a table to make it easy to understand the difference between the two examinations. After providing an explanation of both examinations, any remaining questions were answered by a physician. Subsequently, each participant was allowed to choose either examination procedure. If CTC was selected, a full-laxative bowel preparation $\operatorname{method}^{8}$ or a reduced-laxative method ${ }^{9}$ could be chosen by the participant based on the same written document (Table S1 in Supplementary Material).

\section{Questionnaires}

After the participants selected one of the two colonic examinations, they completed the first questionnaire before the colorectal examination was conducted to determine the reason for their choice of colorectal examination type (Table S2 in Supplementary Material). The questionnaire included nine response options describing possible reasons for their choice of examination type. The items and response options for choosing between 
colonoscopy and CTC are described in Table S2 of Supplementary Material.

To assess participants' experiences during the preparations and procedures, a second three-item questionnaire developed by the authors was completed by participants on the day of the examination (Table S3 in Supplementary Material). Participants who received sedation during colonoscopy were given questionnaires after they recovered from sedation. The first two items asked participants to rate their discomfort related to bowel preparation and to the examination itself using a five-point Likert scale (where 1 indicated very easy; 2, somewhat easy; 3, neutral; 4, somewhat difficult; and 5 , very difficult). The third item asked which part of the examination generated the most discomfort. Participants were allowed to select one or more of the seven responses.

\section{Colonoscopy Procedure}

Colonoscopy was performed at each participating site. For bowel preparation, participants received $2 \mathrm{~L}$ of polyethylene glycol (PEG) solution, 1.8 L of magnesium citrate solution, or $1 \mathrm{~L}$ of polyethylene glycol electrolyte solution with ascorbic acid (MoviPrep ${ }^{\circledR}$ ). The use of antispasmodics and sedatives during colonoscopy was based on the judgment and responsibility of the physician in charge of the examination. The type of gas used for colonic insufflation during colonoscopy was not specified in this study. Polyps discovered during colonoscopy could be removed endoscopically, depending on the judgment of the endoscopist.

\section{CTC Procedure}

For bowel preparation before examination by CTC, participants received either a full laxative preparation $\operatorname{method}^{8}$ or a reduced-laxative preparation method. ${ }^{9}$ Details of these methods are described in previous studies. ${ }^{8,9}$ In summary, the full laxative method consisted of $1,620 \mathrm{~mL}$ of PEG over the course of $2 \mathrm{~h}$, followed by $400 \mathrm{~mL}$ solution consisting of $380 \mathrm{~mL}$ of PEG plus $20 \mathrm{~mL}$ of sodium diatrizoate for tagging of residual fluid. The reduced-laxative method consisted of $760 \mathrm{~mL}$ PEG and $40 \mathrm{~mL}$ sodium diatrizoate for tagging, which was administered one day before CTC. Colonic distention was obtained with an automatic $\mathrm{CO}_{2}$ insufflator using a rectal catheter. CTC examinations were performed with either 64- or 16-channel multi-detector row CT scanners, used single-breath-hold supine and prone positioning, and did not use intravenous contrast medium or sedation.

\section{Statistical Analysis}

For the a priori power calculation, we assumed that the difference between the selection ratio of colonoscopy and CTC would be at least $10 \%$ based on the results of previous studies, ${ }^{13}$ and we assumed that the dropout or withdrawal rate would be $5 \%$. Based on these assumptions, we determined that 863 participants would be necessary for sufficient statistical power (80\%), with an alpha of 0.05 (two-tailed). ${ }^{15}$

We used the binomial exact test to evaluate whether participants preferred CTC or colonoscopy and full laxative or reduced-laxative preparation for CTC. In addition, non-normally distributed data between CTC and colonoscopy were analyzed using the Wilcoxon rank-sum test or the Wilcoxon rank-sum test with continuity correction. The chi-squared tests or the chi-squared test with Yates continuity correction were used for categorical data. All confidence intervals were within 95\%. All $\mathrm{P}$ values involved a hypothesis test against a two-sided alternative, and $\mathrm{P}<0.05$ was considered to indicate statistical significance. These analyses were performed using $\mathrm{R}$ (The R Foundation for Statistical Computing Platform).

\section{Results}

A total of 881 participants were included in this study. Nineteen participants withdrew their informed consent, and 15 participants were excluded based on the exclusion criteria. Data from the questionnaires of the remaining 847 participants (502 men, 345 women; mean age, 60.5 years) were analyzed (Table 1).

\section{Participant's Examination Preference}

Colonoscopy was preferred over CTC; however, almost $1 / 3$ of the participants chose CTC over colonoscopy $(n=607$ participants [72\%] vs $n=240$ participants [28\%], $\mathrm{p}<0.001)$ (Table 1).

Between participants who chose colonoscopy (colonoscopy group) and those who chose CTC (CTC group), there were no significant differences in age, sex, the use of antithrombotic medicine, or the percentage of participants who had previous experience with colonic examinations (Table 1). In the CTC group, reduced-laxative preparation was selected by 157 participants $(65 \%)$ and the full-laxative preparation by 83 participants $(35 \%)$ (Table 2). Reduced-laxative preparation was selected significantly more often by female participants than by male participants $(\mathrm{p}=0.0158)($ Table 2$)$. 
Table I Participant Characteristics

\begin{tabular}{|l|l|l|l|}
\hline & Colonoscopy & CTC & p-value \\
\hline n (\%) & $607(72)$ & $240(28)$ & $<0.00 I^{*}$ \\
Age, mean (y) & 60.2 & 59.8 & $0.54 I^{\dagger}$ \\
Interquartile range & $5 I-69$ & $49-70$ & \\
Sex, male n (\%) & $370(6 \mathrm{I})$ & $132(55)$ & $0.13 \mathrm{I}^{\ddagger}$ \\
Anticoagulant, n (\%) & $5 \mathrm{I}(8.4)$ & $29(12)$ & $0.128^{\ddagger}$ \\
\hline Previous colorectal exam & & & \\
Colonoscopy, n (\%) & $277(46)$ & $95(40)$ & $0.32 I^{\S}$ \\
CTC, n (\%) & $\mathrm{II}(1.8)$ & $4(1.7)$ & \\
Barium enema, n (\%) & $46(7.6)$ & $16(6.7)$ & \\
\hline
\end{tabular}

Notes: *Exact binomial test, ${ }^{\dagger}$ Wilcoxon rank sum test, ${ }^{\ddagger}$ Chi-squared test with Yates' continuity correction, ${ }^{\S} \mathrm{Chi}$-squared test.

Abbreviations: CTC, computed tomographic colonography; n.s., not significant; n, number.

Table 2 Characteristics of Participants That Chose CTC

\begin{tabular}{|l|l|l|l|}
\hline & $\begin{array}{l}\text { Full-Laxative } \\
\text { CTC }\end{array}$ & $\begin{array}{l}\text { Reduced-Laxative } \\
\text { CTC }\end{array}$ & p-value \\
\hline $\mathrm{n}(\%)$ & $83(35)$ & $157(65)$ & $<0.001^{*}$ \\
$\begin{array}{l}\text { Age, mean (y) } \\
\text { Interquartile } \\
\text { range }\end{array}$ & 58.2 & 60.7 & $0.173^{\dagger}$ \\
$\begin{array}{l}\text { Sex, male } \\
\mathrm{n}(\%)\end{array}$ & $55(66)$ & $50-72$ & \\
\hline
\end{tabular}

Notes: *Exact binomial test, ${ }^{\dagger}$ Wilcoxon rank sum test, ${ }^{\ddagger}$ Chi-squared test with Yates' continuity correction.

Abbreviations: CTC, computed tomographic colonography; n.s., not significant; $n$, number.

\section{The Reasons for Choosing a Specific Type of Examination}

The first questionnaire was completed by 846 of the 847 participants (Tables 3 and 4). The reason for choosing
Table 3 Reasons Participants Chose Colonoscopy

\begin{tabular}{|l|l|l|}
\hline & $\mathbf{n = 6 0 6}$ & $\mathbf{( \% )}$ \\
\hline Higher diagnostic accuracy & 384 & 63 \\
Safe procedure & 109 & 18 \\
Comfortable & 47 & 7.8 \\
Sedative medications & 98 & 16 \\
Obtaining biopsy samples and removing colorectal polyps & 522 & 86 \\
Colonoscopy was comfortable for me in my past & 70 & 12 \\
experiences & & \\
CTC was uncomfortable for me in my past experiences & 0 & 0 \\
No radiation exposure & 28 & 4.6 \\
Cost-effective & 15 & 2.5 \\
Other reason & 25 & 4.1 \\
\hline
\end{tabular}

Note: Multiple answers were possible.

Abbreviations: CTC, computed tomographic colonography; n, number.

colonic examination was shown by the response option "the possibility of obtaining biopsy samples and removing colorectal polyps if detected during procedure" being selected most often $(86 \%(522 / 606))$ in the colonoscopy group (Table 3 ). The response option "CTC is comfortable" was most often selected by the CTC group (76\% [63/83]) and $80 \%(125 / 157)$ (Table 4). In the reduced-laxative preparation CTC group, the response option "reduced bowel preparation method" was selected by $59 \%$ (93/157) of participants (Table 4), while this response was not relevant for the standard laxative preparation group.

\section{The Burden of the Preparation and} Examination Procedures

The second questionnaire was completed by 834 of the 847 participants (Table 5). In preparation experience, bowel preparation for CTC was found to be significantly more

Table 4 Reasons Participants Chose CTC

\begin{tabular}{|c|c|c|c|c|c|c|}
\hline & $\begin{array}{l}\text { All } \\
(n=240)\end{array}$ & (\%) & $\begin{array}{l}\text { Full Laxative } \\
(n=83)\end{array}$ & (\%) & $\begin{array}{l}\text { Reduced Laxative } \\
(n=157)\end{array}$ & (\%) \\
\hline Reduced bowel preparation & 93 & 39 & n.a & & 93 & 59 \\
\hline Diagnostic accuracy & 58 & 24 & 27 & 33 & 31 & 20 \\
\hline Safe procedure & 58 & 24 & 23 & 28 & 35 & 22 \\
\hline Comfortable & 188 & 78 & 63 & 76 & 125 & 80 \\
\hline No sedative medications & 56 & 23 & 17 & 21 & 39 & 25 \\
\hline Information about other abdominal organs & 100 & 42 & 36 & 43 & 64 & $4 I$ \\
\hline CTC was comfortable for me in my past experiences & 1 & 0.4 & 0 & 0 & I & 0.6 \\
\hline Colonoscopy was uncomfortable for me in my past experiences & 30 & 13 & 5 & 6.0 & 25 & 16 \\
\hline Cost-effective & 8 & 3.3 & 3 & 3.6 & 5 & 3.2 \\
\hline Other reason & 14 & 5.8 & 7 & 8.4 & 7 & 4.5 \\
\hline
\end{tabular}

Note: Multiple answers were possible.

Abbreviations: CTC, computed tomographic colonography; n, number; n.a. question not applicable. 
Table 5 Results on the Experiences of Colonic Examinations

\begin{tabular}{|c|c|c|c|c|}
\hline & $\begin{array}{l}\text { Colonoscopy } \\
(n=597)\end{array}$ & (\%) & $\begin{array}{l}\text { CTC } \\
(n=237)\end{array}$ & (\%) \\
\hline \multicolumn{5}{|c|}{ QI. Was it difficult to drink laxative for bowel preparation? } \\
\hline Easy & 138 & 23 & 36 & 15 \\
\hline Somewhat easy & 197 & 33 & 69 & 29 \\
\hline Neutral & 70 & 12 & 47 & 20 \\
\hline Somewhat difficult & 158 & 26 & 61 & 26 \\
\hline Very difficult & 34 & 5.7 & 24 & 10 \\
\hline \multicolumn{5}{|c|}{ Q2. How would you rate your experience with the colonic exam? } \\
\hline Easy & 94 & 16 & 27 & II \\
\hline Somewhat easy & 256 & 43 & 118 & 50 \\
\hline Neutral & 113 & 19 & 54 & 23 \\
\hline Somewhat difficult & 100 & 17 & 35 & 15 \\
\hline Very difficult & 34 & 5.7 & 3 & 1.3 \\
\hline \multicolumn{5}{|c|}{ Q3. What part of the colonic exam caused discomfort? (multiple answers possible) } \\
\hline None & 215 & 36 & 60 & 25 \\
\hline Gas insufflation of the intestine & 133 & 22 & $|4|$ & 60 \\
\hline Use of the sleep drug & 10 & 1.7 & n.a. & n.a. \\
\hline Insertion of the endoscope & 80 & 13 & n.a. & n.a. \\
\hline Having to hold breath during the scan & n.a. & & 13 & 5.5 \\
\hline Having to roll over into different positions & n.a. & & 7 & 3.0 \\
\hline Pain & 108 & 18 & 18 & 7.6 \\
\hline Duration of the procedure & 75 & 13 & 11 & 4.6 \\
\hline Other & 93 & 16 & 22 & 9.3 \\
\hline
\end{tabular}

Abbreviations: CTC, computed tomographic colonography; n.a. question not applicable; n, number.

burdensome than that for colonoscopy, with 10\% (24/237) in the CTC group and 5.7\% (34/597) in the colonoscopy group, reporting that it was very difficult to drink the laxative and $15 \%(36 / 237)$ in the CTC group and 23\% (138/597) in the colonoscopy group, which reported that it was easy $(\mathrm{p}=0.003)$ (Figure 1A). The overall experience of the examination itself did not differ between the groups, with little difference in the responses on the Likert scale $(\mathrm{p}=0.582)$ (Figure 1B). Regarding part of the examination that caused most discomfort, "pain" and "duration of the procedure" were experienced significantly more often in the colonoscopy group (18\% (108/597) and 13\% (75/597), respectively) than in the CTC group (7.6\% (18/237) and 4.6\% $(11 / 237)$, respectively) $(p<0.001$ and $p=0.001$, respectively) (Figure 2). The response option "injection of the gas" was the most common cause of discomfort in the CTC group $(60 \%$ [141/237]), and this was experienced more often than in the colonoscopy group $(22 \%$ [133/597]) $(\mathrm{p}<0.001)$ (Figure 2).

\section{Discussion}

We investigated the factors that FIT-positive patients consider when choosing a colorectal examination by investigating the exam preference of FIT-positive patients before the colon examination. A systematic review of studies on stated preference for cancer screening tests showed that attributes, such as efficacy, process, and cost, are significant determinants of choice. ${ }^{16}$ The process includes information provided to patients. However, FIT-positive patients do not provide sufficient information on examination modalities other than colonoscopy in clinical settings. Therefore, there was a dearth of studies that considered patients' decision-making process of selecting the preferred choice of procedure during the assessment. Colonoscopy has the advantage of detecting, diagnosing, and treating lesions in a single examination. In contrast, CTC only detects lesions, and if lesions are found, colonoscopy is required for diagnostic evaluation or treatment. Therefore, colonoscopy is considered to have an advantage over CTC for FIT-positive patients who are more likely to have lesions in the large intestine. In our study, the most common reason for selection given by patients who chose colonoscopy was "obtaining biopsy samples and removing colorectal polyps," and the second most common reason was "higher diagnostic accuracy." The diagnostic accuracy of CTC is considered equivalent to that of colonoscopy for detecting 


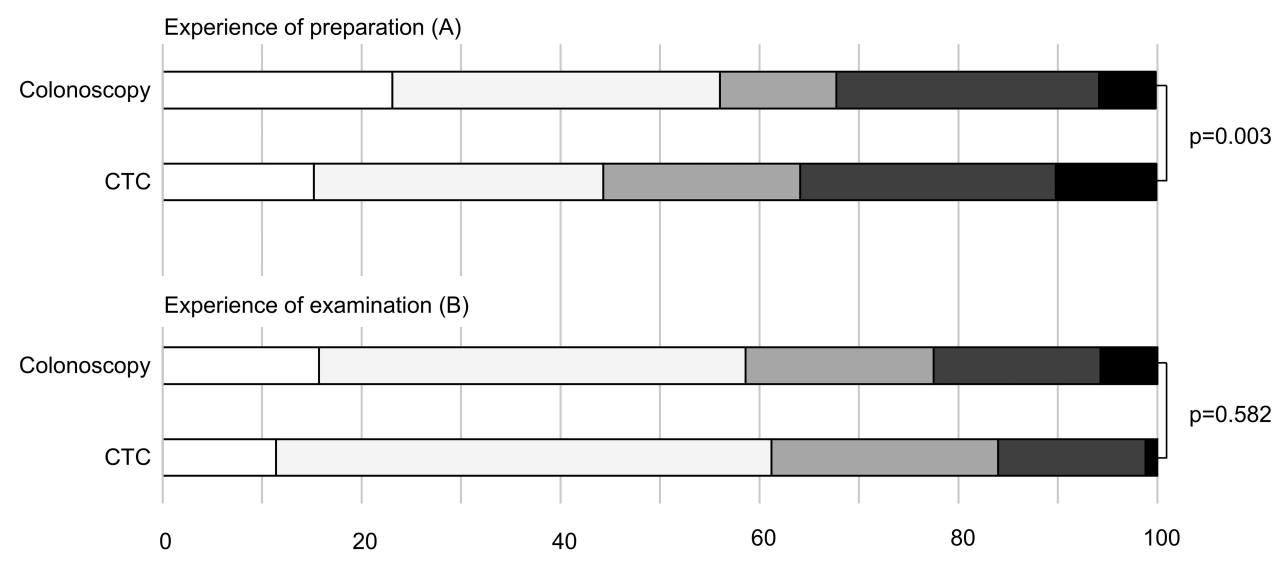

$(\%)$

\begin{tabular}{|ll|}
\hline$\square$ Easy & $\square$ Neutral \\
$\square$ Somewhat easy & $\square$ Somewhat difficult $\quad$ घVery difficult \\
\hline
\end{tabular}

Figure I Experience of preparation and examination for colonoscopy and CTC. Graph of the responses on the survey regarding patients' experiences on preparation (A) and examination (B) for colonoscopy and CTC, Based on surveys of 834 people. The Wilcoxon rank-sum test with continuity correction was used to calculate the p values.

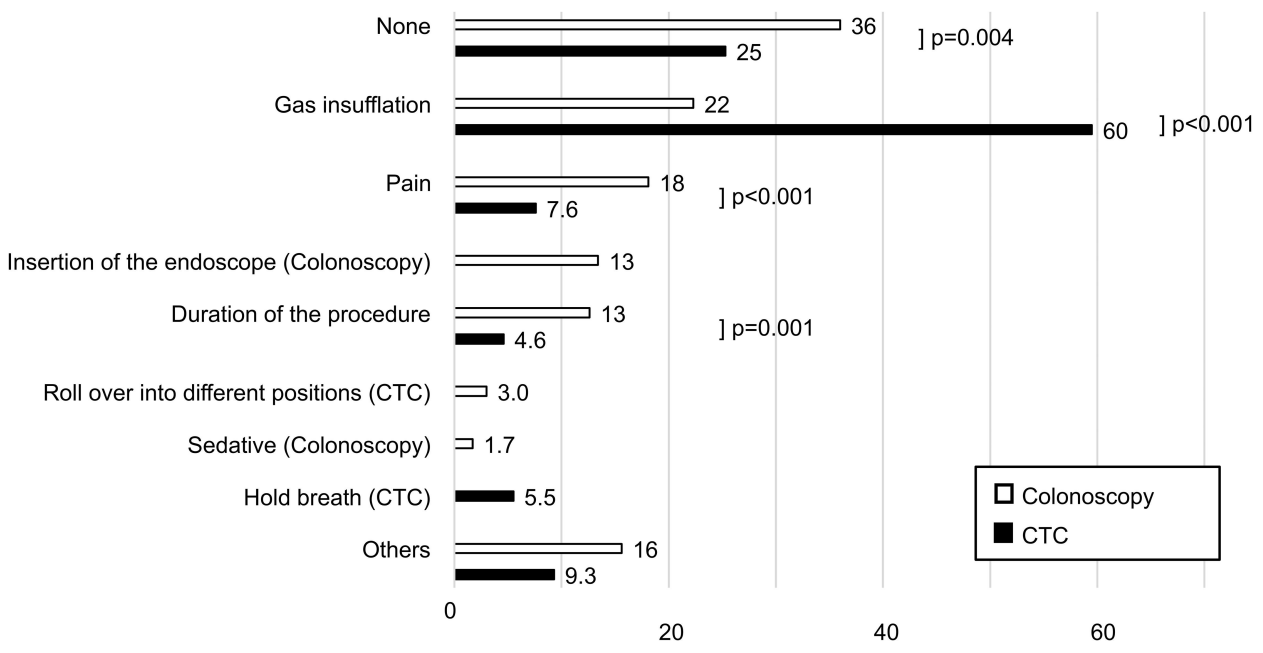

(\%)

Figure 2 Discomfort during the colonic examination. Response to the survey regarding discomfort during colonic examination based on surveys of 834 people. They were allowed to select one or more answers to each question; hence, the total percentage was more than 100. The chi-squared test with Yates' continuity correction was used to calculate the $p$ values.

polyps and cancer with a diameter of $\geq 10 \mathrm{~mm},{ }^{8,9}$ but colonoscopy is superior to CTC in diagnostic accuracy for flat lesions. ${ }^{8}$ According to a discrete choice study investigating patients' preference for colonoscopy or CTC in 130 patients who underwent both examinations because of suspected CRC, the patients preferred colonoscopy to CTC because of the need for a second procedure after CTC, the higher likelihood of missing cancers or polyps with CTC, and higher costs of a CTC test. ${ }^{17}$ Another study reported that the lay public $(\mathrm{n}=100)$, who were presented with information about three types of colorectal examinations, chose colonoscopy,
CTC, and colon capsule endoscopy in $71 \%, 22 \%$, and $7 \%$ of cases, respectively, if the investigation of a positive fecal occult blood test (FOBT) was needed. ${ }^{18}$ The results of these studies are consistent with our results, suggesting that FIT-positive individuals are more likely to opt for colonoscopy after receiving sufficient explanation about both tests. However, the proportion of choices for each examination was not adequately investigated for FIT-positive participants actively scheduled for examination. Our results from a largescale study showed that $72 \%$ of well-informed participants chose colonoscopy. Interestingly, a considerable proportion of 
patients (28\%) chose CTC after fully understanding the advantages of colonoscopy.

The reason that many participants chose CTC was "I think CTC is comfortable." In a multicenter study on patients' experience, it was found that participants assigned a high satisfaction level with CTC, and those with experience of both modalities preferred CTC over optical colonoscopy. ${ }^{19}$ In another study, it was reported that patient acceptance of CTC was significantly higher than that of colonoscopy, and $62 \%$ of patients would choose CT colonography as the first examination if they have a positive FIT result in the future. ${ }^{9}$ Approximately $40 \%$ of those who chose CTC had previously undergone colonoscopy, but few had undergone CTC. Thus, it seems more appropriate to consider that participants avoided colonoscopy rather than actively chose CTC. Several reports indicated that patients consider colonoscopy distressing or burdensome. ${ }^{18,20}$ It was found that the most decisive reason not to participate in screening by colonoscopy was the unpleasantness of the examination. ${ }^{21}$ In addition, many patients consider the burden of the preparation to be greater than that of the colorectal examination itself. $^{22,23}$ In comparative studies of full-laxative colonoscopy and reduced or no laxative CTC, CTC was chosen as the preferred test by the majority of participants against colonoscopy. ${ }^{9,24}$ Our results also showed that $65 \%$ of the participants who underwent CTC chose reduced-laxative preparation. The participants who chose full-laxative preparation appeared to value the higher diagnostic accuracy of the procedure with full-laxative preparation compared to reduced-laxative preparation. Our study highlights the fact that although colonoscopy is often considered as a preferred method, there might be finer aspects to patients' preference. To reinforce the patient's decision-making process to a more informed one, efforts should be made to include discussions on the benefits and uncertainties associated with all the options. Our experimental approach for providing detailed information sheet addressed this concern.

Currently, the criteria for active recommendation of CTC in place of colonoscopy as the first examination are only the patient's refusal of colonoscopy or the presence of a contraindication for colonoscopy. ${ }^{11}$ A report of a national screening program in the UK revealed that in 52,202 patients with a positive FOBT result, colonoscopy was performed in 50,975 patients $(97.6 \%)$, whereas CTC was performed in only 1970 patients $(3.7 \%){ }^{25}$ If FIT-positive patients can freely choose the examination method as they did in our study, CTC may be performed as a detailed examination more often, which may reduce the number of colonoscopies.
In evaluating the post-examination experience, the proportion of participants who responded that bowel preparation was burdensome in the CTC group was significantly higher than in the colonoscopy group, although $65 \%$ of the participants underwent CTC with reduced-laxative preparation. No significant difference was observed between the colonoscopy and CTC groups in the overall experience of the procedure itself. Many reports based on surveys conducted in patients who underwent both types of examinations showed a higher preference for CTC. ${ }^{13,14}$ However, these results are not consistent with a questionnaire conducted among patients who underwent only one of the examinations. Based on the questionnaire by Plumb et al, ${ }^{25}$ many patients unexpectedly found CTC to present greater discomfort than colonoscopy. The patients chose CTC because they expected it to be easier and more comfortable. Thus, the patients might feel more burdened than expected in the actual examination. According to our results, almost $60 \%$ of the participants who underwent CTC responded that the gas injection generated the most discomfort. Before the procedure, patients should be informed that gas injection can be burdensome.

Our study has several limitations. The study participants were all visiting a medical institution for diagnostic examination after receiving a positive FIT result, while those with a positive FIT result that did not visit a medical institution for examination were not included. Fear of colonoscopy is reported as one of the main reasons for lack of follow-up colonoscopy among persons with a positive FOBT result. $^{26}$ Another study is needed to determine the selectivity and acceptability of CTC in patients with positive FOBT results that did not visit a medical institution for follow-up examination. In addition, our study did not include a comprehensive account of factors that can influence patients' perspectives of treatment procedures.

Since the diagnostic performance of CTC for superficial lesions differs among reports, ${ }^{8,9,27,28}$ the actual diagnostic performance was not described in the document that patients were given before making their decision. However, it was noted that CTC has a reduced capacity for diagnosing superficial lesions. In addition, the actual percentage of patients who require colonoscopy after undergoing CTC was not presented in the document because the indications for endoscopic treatment for colorectal polyps differ among institutions. The possibility that the lack of information about these factors affected the rate of selection of the type of examination cannot be ruled out. 
The patient's knowledge of the actual percentage might have affected their decision. During the preparation of the information documents about both procedures, a statement that CTC is less uncomfortable was included. CTC was less uncomfortable than colonoscopy in a Japanese multicenter study. ${ }^{9}$ However, the opposite results have also been published, ${ }^{29}$ and it must therefore be noted that these opposing results were reported from another country. Furthermore, it is not possible to rule out the possibility that inclusion of this statement will affect selection rates. Cost has been reported as a barrier to colonoscopy. ${ }^{30} \mathrm{We}$ found no major differences between the costs of CTC and colonoscopy in our country. However, conditions are different overseas, and there may therefore be differences in the selection rates due to cost.

\section{Conclusions}

Currently, the majority of those with positive FIT results undergo detailed examination via colonoscopy. However, a fraction of individuals with positive FIT results will attempt to avoid colonoscopy at all costs. We found that when FITpositive individuals were given a choice, almost one-third of the participants chose CTC, as they thought it would be a more "comfortable" examination. Clinicians should therefore be aware of patients' potential preference for noninvasive colorectal examinations. In addition, CTC can serve a supplementary role for the ever-increasing demand for colonoscopy, and this may lead to more efficient use of CTC.

\section{Data Sharing Statement}

The datasets generated during and/or analysed during the current study are available from the corresponding author on reasonable request.

\section{Acknowledgments}

Editorial support, in the form of medical writing, assembling tables and creating high-resolution images based on authors' detailed directions, collating author comments, copyediting, fact checking, and referencing, was provided by Editage, Cactus Communications.

\section{Disclosure}

Junta Yamamichi reports personal fees from Canon Inc. and Mitsubishi Chemical Corp., outside the submitted work. The authors report no other potential conflicts of interest in this work.

\section{References}

1. Bray F, Ferlay J, Soerjomataram I, Siegel RL, Torre LA, Jemal A. Global cancer statistics 2018: GLOBOCAN estimates of incidence and mortality worldwide for 36 cancers in 185 countries. CA Cancer J Clin. 2018;68(6):394-424. doi:10.3322/caac.21492

2. Torre LA, Bray F, Siegel RL, Ferlay J, Lortet-Tieulent J, Jemal A. Global cancer statistics, 2012. CA Cancer J Clin. 2015;65(2):87-108. doi: $10.3322 /$ caac. 21262

3. Schreuders EH, Ruco A, Rabeneck L, et al. Colorectal cancer screening: a global overview of existing programmes. Gut. 2015;64 (10):1637-1649. doi:10.1136/gutjnl-2014-309086

4. Blom J, Kilpelainen S, Hultcrantz R, Tornberg S. Five-year experience of organized colorectal cancer screening in a Swedish population - increased compliance with age, female gender, and subsequent screening round. J Med Screen. 2014;21(3):144-150. doi:10.1177/ 0969141314545555

5. Carlson CM, Kirby KA, Casadei MA, Partin MR, Kistler CE, Walter LC. Lack of follow-up after fecal occult blood testing in older adults: inappropriate screening or failure to follow up? Arch Intern Med. 2011;171(3):249-256. doi:10.1001/archinternmed.2010.372

6. Bowles CJ, Leicester R, Romaya C, Swarbrick E, Williams CB, Epstein O. A prospective study of colonoscopy practice in the UK today: are we adequately prepared for national colorectal cancer screening tomorrow? Gut. 2004;53(2):277-283. doi:10.1136/ gut.2003.016436

7. Macfarlane M, Leicester L, Romaya R, Epstein E. Colonoscopy services in the United Kingdom. Endoscopy. 1999;31(6):409-411. doi:10.1055/s-1999-8040

8. Nagata K, Endo S, Honda T, et al. Accuracy of CT colonography for detection of polypoid and nonpolypoid neoplasia by gastroenterologists and radiologists: a nationwide multicenter study in Japan. Am J Gastroenterol. 2017;112(1):163-171. doi:10.1038/ajg.2016.478

9. Utano K, Nagata K, Honda T, et al. Diagnostic performance and patient acceptance of reduced laxative CT colonography for the detection of polypoid and non-polypoid neoplasms: a multicenter prospective trial. Radiology. 2017;282(2):399-407. doi:10.1148/ radiol.2016160320

10. Moreno C, Kim DH, et al. ACR appropriateness criteria((r)) colorectal cancer screening. J Am Coll Radiol. 2018;15(5S):S56-S68. doi:10.1016/j.jacr.2018.03.014

11. Sali L, Grazzini G, Mascalchi M. CT colonography: role in FOBT-based screening programs for colorectal cancer. Clin J Gastroenterol. 2017;10 (4):312-319. doi:10.1007/s12328-017-0744-1

12. Saito H, Kanaoka S, Shimada T, et al. The placement of large intestinal CT exam as a method of detailed checkup, as well as its necessary conditions and issues. $J$ Gastroenterol Cancer Screen. 2016;54(3):425-441.

13. Lin OS, Kozarek RA, Gluck M, et al. Preference for colonoscopy versus computerized tomographic colonography: a systematic review and meta-analysis of observational studies. J Gen Intern Med. 2012;27(10):1349-1360. doi:10.1007/s11606-012-2115-4

14. Gareen IF, Siewert B, Vanness DJ, Herman B, Johnson CD, Gatsonis C. Patient willingness for repeat screening and preference for CT colonography and optical colonoscopy in ACRIN 6664: the National CT Colonography trial. Patient Prefer Adherence. 2015;9:1043-1051. doi:10.2147/PPA.S81901

15. Chow S-C, Shao J, Wang H. Sample Size Calculations in Clinical Research. 2nd ed. 2008.

16. Mansfield C, Tangka FK, Ekwueme DU, et al. Stated preference for cancer screening: a systematic review of the literature, 1990-2013. Prev Chronic Dis. 2016;13:E27. doi:10.5888/pcd13.150433

17. Howard K, Salkeld G, Pignone M, et al. Preferences for CT colonography and colonoscopy as diagnostic tests for colorectal cancer: a discrete choice experiment. Value Health. 2011;14(8):1146-1152. doi:10.1016/j.jval.2011.07.012 
18. Ojidu H, Palmer H, Lewandowski J, et al. Patient tolerance and acceptance of different colonic imaging modalities: an observational cohort study. Eur J Gastroenterol Hepatol. 2018;30(5):520-525. doi:10.1097/MEG.0000000000001090

19. Pooler BD, Baumel MJ, Cash BD, et al. Screening CT colonography: multicenter survey of patient experience, preference, and potential impact on adherence. AJR Am J Roentgenol. 2012;198(6):1361-1366. doi:10.2214/AJR.11.7671

20. Denters MJ, Deutekom M, Bossuyt PM, Fockens P, Dekker E. Patient burden of colonoscopy after positive fecal immunochemical testing for colorectal cancer screening. Endoscopy. 2013;45(5):342-349. doi: $10.1055 / \mathrm{s}-0032-1326238$

21. de Wijkerslooth TR, de Haan MC, Stoop EM, et al. Reasons for participation and nonparticipation in colorectal cancer screening a randomized trial of colonoscopy and CT colonography. Am J Gastroenterol. 2012;107(12):1777-1783. doi:10.1038/ajg.2012.140

22. van Gelder RE, Birnie E, Florie J, et al. CT Colonography and colonoscopy assessment of patient preference in a 5-week follow-up study. Radiology. 2004;233(2):328-337. doi:10.1148/radiol.2331031208

23. Ristvedt SL, McFarland EG, Weinstock LB, Thyssen EP. Patient preferences for CT colonography, conventional colonoscopy, and bowel preparation. Am J Gastroenterol. 2003;98(3):578-585. doi:10.1111/j.1572-0241.2003.07302.x

24. Zalis ME, Blake MA, Cai W, et al. Diagnostic accuracy of laxative-free computed tomographic colonography for detection of adenomatous polyps in asymptomatic adults: a prospective evaluation. Ann Intern Med. 2012;156(10):692-702. doi:10.7326/ 0003-4819-156-10-201205150-00005
25. Plumb AA, Ghanouni A, Rees CJ, et al. Patient experience of CT colonography and colonoscopy after fecal occult blood test in a national screening programme. Eur Radiol. 2017;27(3):1052-1063. doi:10.1007/s00330-016-4428-x

26. Llovet D, Serenity M, Conn LG, et al. Reasons for lack of follow-up colonoscopy among persons with a positive fecal occult blood test result: a qualitative study. Am J Gastroenterol. 2018;113(12):1872-1880. doi:10.1038/s41395-018-0381-4

27. Suzuki N, Ignjatovic A, Burling D, Taylor SA. CT colonography and non-polypoid colorectal neoplasms. Gastrointest Endosc Clin N Am. 2010;20(3):565-572. doi:10.1016/j.giec.2010.03.011

28. Utano K, Katsuki S, Matsuda T, et al. Colon capsule endoscopy versus CT colonography in patients with large non-polypoid tumours: a multicentre prospective comparative study (4CN Study). Digestion. 2019;1-9.

29. Akerkar GA, Yee J, Hung R, McQuaid K. Patient experience and preferences toward colon cancer screening: a comparison of virtual colonoscopy and conventional colonoscopy. Gastrointest Endosc. 2001;54(3):310-315. doi:10.1067/mge.2001.117595

30. Decruz GM, Ng CH, Lim KT, et al. Afterthoughts on colonoscopy was it that bad?. J Med Screen. 2020;969141320923381.
Patient Preference and Adherence

\section{Publish your work in this journal}

Patient Preference and Adherence is an international, peer-reviewed, open access journal that focusing on the growing importance of patient preference and adherence throughout the therapeutic continuum. Patient satisfaction, acceptability, quality of life, compliance, persistence and their role in developing new therapeutic modalities and compounds to optimize clinical outcomes for existing disease

\section{Dovepress}

states are major areas of interest for the journal. This journal has been accepted for indexing on PubMed Central. The manuscript management system is completely online and includes a very quick and fair peer-review system, which is all easy to use. Visit http:// www.dovepress.com/testimonials.php to read real quotes from published authors. 